\section{Surface Characteristics of Reciprocating Instruments Before and After Use - A SEM Analysis}

Aida Rene Assayag Hanan1, Daniely Amorin de Meireles', Emílio Carlos Sponchiado Júnior ${ }^{1}$, Simone Hanan ${ }^{1}$, Milton Carlos Kuga ${ }^{2}$, Idomeo Bonetti Filho ${ }^{2}$

The presence of debris, defects and deformations of endodontic reciprocating instruments before and after chemical-mechanical preparation (MCP) was analyzed using scanning electron microscopy (SEM). The following 26 instruments were divided into 2 groups: Waveone $(n=13)$ and Reciproc $(n=13)$ and examined by SEM (150x magnification) prior to canal preparation at 2 and $4 \mathrm{~mm}$ from the tip. The instruments were used in the preparation of mesial root canals of 26 extracted human permanent mandibular molars. The instruments were then washed in ultrasonic bath and subjected to new microscopic analysis of debris and deformation by a score that used the presence or absence of irregular edges, grooves, microcavities and burrs as criteria. After the SEM analysis and with the scores of the examiners, the collected data were subjected to descriptive statistical analysis using the Kruskall-Walis and Mann Whitney test at a 5\% significance level. All instruments examined presented debris before and after use. A statistically significant difference was found for defects and deformation between the groups $(p<0.05)$. The presence of defects and deformities was higher in the WaveOne instruments, and Reciproc instruments presented a lower rate.

\author{
'Dental School, UFAM - Federal \\ University of Amazonas, \\ Manaus, AM, Brazil \\ ${ }^{2}$ Araraquara Dental School, \\ UNESP - Univ Estadual Paulista, \\ Araraquara, SP, Brazil
}

Correspondence: Emílio Carlos Sponchiado Júnior, Rua Maceió, 711, ed. El Grecco, apto 501B, 69057-010 Manaus, AM, Brasil. Tel: +55-92-98194-6444. e-mail: spemilio@ufam.edu.br

Key Words: reciprocating motion, nickel-titanium file, microscopy.

\section{Introduction}

An important innovation in the field of dentistry has been the introduction of nickel-titanium alloy instruments in recent years. Superelasticity and shape memory are the main mechanical properties of this alloy, but different manufacturing strategies have been continuously proposed to improve the mechanical properties of $\mathrm{Ni}$-Ti instruments, such as flexibility, resistance to fatigue, fracture and risk of fracture. They include different thermomechanical treatments, changes in the chemical and manufacturing process of the alloy and cross-sectional design. Thus, the instruments made from M-Wire alloy should have greater flexibility and fatigue resistance than those from conventional $\mathrm{Ni}$-Ti instruments (1).

In addition, changes in the modes of endodontic instrument use were also suggested: the WaveOne instruments (Dentsply Maillefer) were designed to work in reciprocating motion and they determine the range of motion of rotation to the right and left, which has been shown to increase service life and fatigue resistance of $\mathrm{Ni}-\mathrm{Ti}$ instruments (2-6).

The three Reciproc files have regressive taper: R25 (25.08), R40 (40.06) and R50 (50.05). The instruments are made from $\mathrm{M}$-Wire nickel-titanium alloy which presents greater flexibility and cyclic fatigue resistance than the traditional nickel-titanium alloys. They have an S-shaped cross-sectional design. The Reciproc instruments alternate between $150^{\circ}$ counterclockwise and $30^{\circ}$ clockwise rotation and they are used at 10 reciprocation cycles per second, equivalent to approximately $300 \mathrm{rpm}(7,8)$.
The WaveOne system consists of three instruments made from M-Wire nickel-titanium alloys, called Small (21.06), Primary (25.08) and Large (40.08). They have a modified convex triangular cross-section at the tip and convex triangular cross-section in the middle and coronal portion. The WaveOne instruments alternate between $170^{\circ}$ counterclockwise and $50^{\circ}$ clockwise rotation (8).

The surface evaluation of new and used $\mathrm{Ni}$-Ti instruments has been previously studied $(9,10)$. However, this is probably one of the few studies reported to date on the evaluation of surface characteristics of the cutting blades of the Reciproc and Waveone reciprocating instruments.

In view of the new reality of the reciprocating systems, it is pertinent to evaluate in vitro the presence of debris and surface characteristics of the WaveOne and Reciproc reciprocating $\mathrm{Ni}-\mathrm{Ti}$ instruments by scanning electron microscopy (SEM) before and after use, contributing to further the knowledge of the characteristics and performance of these instruments.

\section{Material and Methods}

A non-random convenience sample of reciprocating files of WaveOne (Dentsply/Maillefer, Ballaigues, Switzerland) and Reciproc (VDW GmbH, Munich, Germany) brands were used to prepare the root canal of 26 mesial roots of mandibular molars, which were analyzed before and after use. The files were divided into two groups: Group WO - WaveOne and Group R - Reciproc. The design of the study was approved by the Research Ethics Committee of the Federal University of Amazonas, protocol number CAAE 
05784412.4.0000.5020.

Twenty-six extracted human mandibular molars were selected with fully formed $16 \mathrm{~mm}$ long roots, provided by the tooth bank of the Dental School of the Federal University of Amazonas, Brazil. After preliminary selection, the teeth were numbered to facilitate tabulation of data and then grouped in a strip of utility wax containing 10 teeth.

To calculate the angle and the radius of curvature of the mesial roots according to the method proposed by Schneider (11) and Pruett et al. (12), orthoradial radiographs were taken using occlusal films with $0.5 \mathrm{~s}$ exposure time and 10 $\mathrm{cm}$ focus-film distance for visualization and measurement of the degree and radius of curvature. On each occlusal film were radiographed 10 teeth. Radiographs were digitized and imported into AutoCad 2012 program for calculations.

To standardize the sample, the length of all teeth was $16 \mathrm{~mm}$, measured by a digital caliper (Mitutoyo, São Paulo, $\mathrm{SP}$, Brazil). The coronal portion of teeth measuring more than $16 \mathrm{~mm}$ was cut with a diamond disk (KG Sorensen, São Paulo, SP, Brazil) mounted on a hand piece until the required length was obtained. Access surgery was then performed using a round diamond bur No. 1015 (KG Sorensen) mounted on a high-speed hand piece. Compensatory wear of the bur (Dentsply/Maillefer), under constant cooling.

To determine the working length (WL), a size $10 \mathrm{~K}$-type file (Dentsply/Maillefer) was introduced into the mesial canals in apical direction until its tip was seen in the foramen. To determine the $\mathrm{WL}$, the file was withdrawn 1 $\mathrm{mm}$ from the obtained length. The presence of independent foramina was identified in the mesial canals by inserting size $10 \mathrm{~K}$-type files (Dentsply/Maillefer). Teeth with mesial canals that ended in only one foramen were excluded.

To standardize the anatomic diameter, size $15 \mathrm{~K}$-type files (Dentsply Maillefer) were introduced in the root canal system so that the tip penetrated and fit the apical foramen in WL to define the reciprocating instruments to be used.

\section{Fabrication of Test Specimens}

Prior to the specimen preparation, the apexes of the selected teeth were covered with utility wax so that the acrylic resin did not outflow into the apical foramen.

Each tooth was placed with a Godiva (New DFL, Rio de Janeiro, RJ, Brazil) at the tip of the anatomical delineator (BIOART B2, São Carlos, SP, Brazil) so it was inserted parallel to the mold. Then, some colorless self-curing acrylic resin (VipiFlash, São Paulo, SP, Brazil) was prepared and added to the silicone mold before placing the tooth. After polymerization, the resin blocks were randomly divided into two groups of 13 teeth each.

Twenty-six new instruments (13 WaveOne and 13 Reciproc files) were removed from packaging for microscopic analysis without any cleaning treatment, because they were sterile. Using required personal protective equipment and clinical tweezers, the operator held the endodontic instruments by the shank in order not to interfere in the results of the experiment and placed them in utility wax in the SEM sample holder. These samples were analyzed by scanning electron microscope (Fei Quanta 250, Toronto, Canada).

Five files were placed on the SEM holder, using one point in instrument shank (groove detail facing up) as a reference for image reading of the cutting blade (active part) of each file, and the second set of images with the groove detail facing downwards so that the active portion of the file could be seen on both sides.

After visualization of each file, the images of the cutting blade (active part) processed and the SEM micrographs were taken at two points: one from $2 \mathrm{~mm}$ from the tip of the instrument and other $4 \mathrm{~mm}$ from maximum curvature of the root, using standard 150x magnification. For microscopic reading of the instruments, all SEM micrographs were recorded on a CD-ROM and inserted into PowerPoint program for the examiners' observation. After taking the SEM micrographs, the instruments were numbered and stored in closed polypropylene tubes.

\section{Instrumentation of the Root Canal Systems}

All instruments were used in permanent rotation in a VDW Silver electric motor (VDW GmbH) with contra-angle 6:1 reduction (Sirona, Bensheim, Germany) and limited torque. To ensure greater stability of chemical-mechanical preparation, the specimens were mounted on a vise to standardize the instrumentation. Each file was used in a single tooth (mesial canals), according to the manufacturers' recommendations. After the introduction and removal of each instrument, the canals were irrigated with a plastic syringe and 29 gauge NaviTip (Ultradent, South Jordan, UT, USA) using $2 \mathrm{~mL}$ of $2.5 \% \mathrm{NaOCI}$.

The root canals in Group WO were instrumented with the WaveOne system (Dentsply Maillefer) according to the manufacturer's recommendations. Initially a glide path was established with size $10 \mathrm{~K}$-type files (Dentsply Maillefer) followed by instrumentation with size $15 \mathrm{~K}$-type file in the WL and the Primary 25.08 WaveOne file (Dentsply Maillefer), in accordance with the predefined system of the WaveOne ALL program. The 25.08 WaveOne file was passively introduced using in-and-out pecking motion with a maximum range of 3 to $4 \mathrm{~mm}$; after reaching 3 $\mathrm{mm}$, the instrument was withdrawn and its active tip was cleaned with gauze imbedded in $2.5 \% \mathrm{NaOCl}$, and the root canal was aspirated and flooded again. The kinematics was performed at least three times until the WL was reached. A size $10 \mathrm{~K}$-type file was used to verify patency in the WL. 
The root canals in Group $\mathrm{R}$ were instrumented with Reciproc system (VDW GMBH) according to the manufacturer's recommendations. Initially a glide path was established with size $10 \mathrm{~K}$-type files, followed by instrumentation with size $15 \mathrm{~K}$-type file in the $\mathrm{WL}$ and the Reciproc file 25.08 (VDW Gmbh) using electric motor in the Reciproc ALL predefined system. The selected instrument was introduced passively using in-and-out pecking motion with a maximum range of 3 to $4 \mathrm{~mm}$; after reaching 3 $\mathrm{mm}$, the instrument was withdrawn and its active tip was cleaned with gauze imbedded in $2.5 \% \mathrm{NaOCl}$, and the root canal was aspirated and flooded again. The kinematics was performed at least three times until the WL was reached. A size $10 \mathrm{~K}$-type file was used to verify patency in the WL.

After instrumentation, the files were submitted to thermo-chemical cleaning in an ultrasonic bath (Cristófoli, Campo Mourão, PR, Brazil) using a heating system for 10 min with water/enzymatic detergent Endozime (DFL) at a ratio of $5 \mathrm{~mL}$ per liter of water.

After the cleaning process, the instruments were properly dried and stored in closed polypropylene tubes in a dust- and dirt-free environment before next SEM analysis, according to the previously described protocol.

\section{Analysis of SEM micrographs}

The images obtained before and after instrumentation of the root canals were analyzed by two previously calibrated examiners by intra- and inter-examiner Kappa test ( 0.92 and 0.91 , respectively) to observe any changes and manufacturing failures of the cutting blades. Presence or absence of debris at the examined sites was also considered.

The examiners received a spreadsheet containing the instrument number, the evaluated location and the side of the instrument (detail facing up or down), and the criteria for evaluation of defects and deformation. The images were projected on Power Point, identified by an Arabic numeral (1 to 208).

To establish the scores, the examiners observed and analyzed the images of the files on a computer screen before and after use to identify the presence of irregular edges,

Table 1. Type of defects observed in the instruments up to $4 \mathrm{~mm}$ of their active part, before and after use

\begin{tabular}{|c|c|c|c|c|c|c|c|c|}
\hline \multirow{2}{*}{ Group } & \multicolumn{2}{|c|}{ lrregular edges } & \multicolumn{2}{|c|}{ Grooves } & \multicolumn{2}{|c|}{ Microcavities } & \multicolumn{2}{|c|}{ Burrs } \\
\hline & $2 \mathrm{~mm}$ & $2-4 \mathrm{~mm}$ & $2 \mathrm{~mm}$ & $2-4 \mathrm{~mm}$ & $2 \mathrm{~mm}$ & $2-4 \mathrm{~mm}$ & $2 \mathrm{~mm}$ & $2-4 \mathrm{~mm}$ \\
\hline WaveOne (before use) & 13 & 13 & 12 & 13 & 0 & 0 & 12 & 12 \\
\hline Reciproc (before use) & 9 & 7 & 2 & 0 & 1 & 1 & 0 & 0 \\
\hline WaveOne (after use) & 13 & 13 & 12 & 11 & 2 & 1 & 11 & 12 \\
\hline Reciproc (after use) & 10 & 10 & 2 & 2 & 1 & 0 & 1 & 1 \\
\hline
\end{tabular}

*Distance from the instrument tip. grooves, microcavities and burrs, using the four different scores adopted by Troian et al. (13), namely: 1 - long axis of the file with no superficial defects; 2 - long axis of the file with approximately one to three areas of superficial defects; 3 - long axis of the file with approximately four to five areas of superficial defects; 4 - long axis of the file with more than five areas of superficial defects.

To perform the analysis, the examiners were previously instructed that in case of any doubt between scores, the higher score should be chosen.

Data were analyzed in GraphPad Prism 4.0 (GraphPad Software, La Jolla, CA, USA). Descriptive statistics was used for the results and the Mann-Whitney test for data analysis of debris and the Kruskal-Wallis test for the remaining analyses was used to compare continuous variables between groups. The level of significance was set at $5 \%$ for all analyses.

\section{Results}

\section{Analysis of Debris}

Debris were present in all WaveOne and Reciproc instruments $[26 \pm 0(100 \%)]$ before and after use $(p>0.05)$.

\section{Qualitative Analysis of Defects and Deformation of the Instruments}

The results of the instruments defects (irregular edges, grooves, microcavities and burr) before and after use are available in Table 1.

The analysis results of the irregular edge defect showed that the WaveOne instruments, prior to use in both assessed lengths presented a larger number of irregular edge defects $(p<0.05)$ compared with the Reciproc instruments.

The results of the groove defect showed that the WaveOne instruments, prior to use in both assessed lengths presented a larger number of defects $(\mathrm{p}<0.05)$ compared with the Reciproc instruments. Few microcavity-type defects were found at the two time intervals and lengths assessed in this study ( $>0.05$ ).

Statistical analysis of the results of the burr defect showed that, prior to use in both lengths, the WaveOne instruments presented a larger number of burr defects $(p<0.05)$ compared with the Reciproc instruments. Comparisons between the instruments of the same brand before and after use showed no statistically significant difference for all defects analyzed separately 
$(p>0.05)$.

\section{Analysis by the Score of Defects and Deformation}

The mean scores of the Reciproc instruments before use at $2 \mathrm{~mm}$ from the tip and from 2 to $4 \mathrm{~mm}$, were 1.76 and 1.61, respectively; and the mean scores for the same lengths after use were 1.84 and 1.85 , respectively ( $p>0.05)$.

The mean values of the WaveOne instruments before use in the classification score, at $2 \mathrm{~mm}$ from the tip and from 2 to $4 \mathrm{~mm}$, were 2.85 and 3.0, respectively; the mean values of the lengths after use were 2.54 and 2.69, respectively $(p<0.05)$.

Table 2 indicates the results of mean scores before and after use in the tip up to $4 \mathrm{~mm}$ from the active part in the instruments regarding the classification score of defects and deformation.

The mean values of the sample posts were compared two by two and revealed that both evaluated lengths of the Wave0ne instruments prior to use presented a larger number of defects and deformation than the Reciproc instruments $(p<0.01)$.

Cross-comparisons between WaveOne and Reciproc instruments at both lengths after use showed that the Reciproc instruments had a significantly better performance $(p<0.01)$ regarding the original physical characteristics.

Figures 1 and 2 are examples of superficial irregularities and debris.

\section{Discussion}

Alongside the improvement of surgical techniques, the available instruments have also been modified to allow better shaping of the root canal, greater elasticity and flexibility, reducing possible deformation of the root canal and providing safety regarding the absence of fracture. The instruments used in this study are for single use, a characteristic that could prevent deterioration of the metal due to prolonged clinical use, which reduces, but does not eliminate, the risk of fatigue or fracture $(14,15)$.

The cumulative effect of multiple clinical uses on the incidence of fatigue fracture of reciprocating instruments have been investigated by different authors. Burklein et

Table 2. Mean scores attributed before and after instrument use up to $4 \mathrm{~mm}$ of their active part

\begin{tabular}{lccc}
\hline Length/moment & Reciproc & WaveOne & $\mathrm{p}$ value \\
\hline 0-2 mm/before use & $1.76 \pm 0.59$ & $2.85 \pm 0.38$ & $\mathrm{p}<0.01$ \\
$2-4 \mathrm{~mm} /$ before use & $1.61 \pm 0.50$ & $3.0 \pm 0.0$ & $\mathrm{p}<0.01$ \\
$0-2 \mathrm{~mm} /$ after use & $1.84 \pm 0.37$ & $2.54 \pm 0.52$ & $\mathrm{p}<0.01$ \\
$2-4 \mathrm{~mm} /$ after use & $1.85 \pm 0.38$ & $2.69 \pm 0.63$ & $\mathrm{p}<0.01$ \\
\hline
\end{tabular}

al. (16) showed that single-use Reciproc R25 instrument could be safely used in 4 root canals without fracture, while Gavini et al. (15) reported that these instruments can resist 1787.78 cycles on average, the double than usual, in reciprocating motion before fracture.

Although manufacturers recommend using the Reciproc and WaveOne files in a single tooth, Park et al. (17) and Caballero et al. (18) concluded that the Reciproc files could be used in 5 or 9 root canals, respectively, without causing anatomical deformities. These results should be evaluated with caution as mechanical deformations of the file can reduce its biomechanical efficiency.

The Reciproc system has S-shaped cross-sectional design that occupies the whole active part of the instrument, while in the WaveOne system has radial surface at the tip that changes to a convex triangular shape in the middle. During instrumentation of curved canals, the instruments with a triangular cross-section, greater flexibility, are claimed by the manufacturer to offer greater distribution of stress throughout its length and the lowest concentrations of stress when compared with the S-shaped, square or rectangular cross-sectional design, being less vulnerable to plastic deformations. However, from the findings of the present study, the Reciproc files presented a lower rate of defects and deformations compared with those observed in the cutting blades of the WaveOne file in a previous study (19).

The presence of debris (excess or metal particles) and superficial defects in the cutting edges of new instruments due to machining, as well as defects and deformations in the morphology of the files, have been reported as observed in this study. Chianello et al. (10) observed that no new $\mathrm{Ni}-\mathrm{Ti}$ instrument was free from imperfections and most presented from 2 to 7 types of surface defects.

It is important to point out that the presence of imperfections found in new instruments may contribute to the deterioration of the instrument or can lead to larger defects (9). The improvement of surface finishing of these instruments could reduce deterioration in multiple uses.

Although the reciprocating instruments used in the present study have been previously sterilized by the manufacturer, all samples presented debris on their cutting blades before and after use. A previous study comparing preoperatively the ProTaper, Waveone and Reciproc instruments showed similar structural defects, confirming that the manufacturing process of $\mathrm{Ni}-\mathrm{Ti}$ instruments usually results in excessive metal and irregular surface, which are characterized by irregular edges, grooves, burrs and microcavities.

The WaveOne files showed a larger number of defects and deformations (irregular edge, groove, burr), differing statistically from the Reciproc files. These results agree 
with those of Pedulla et al. (21) Plotino et al. (22), who demonstrated that the Reciproc files have better physical properties than WaveOne, particularly regarding cyclic fatigue resistance. Fatma and Ozgur (20) also observed postoperatively more irregular surfaces in the Primary WaveOne instrument. This fact could also be further evidenced by the higher mean scores obtained when analyzing the defects and deformations before and after use of the Primary WaveOne instruments, which showed one to five areas with defects and deformations when compared with the Reciproc files.

With respect to the mean scores, it was observed that the
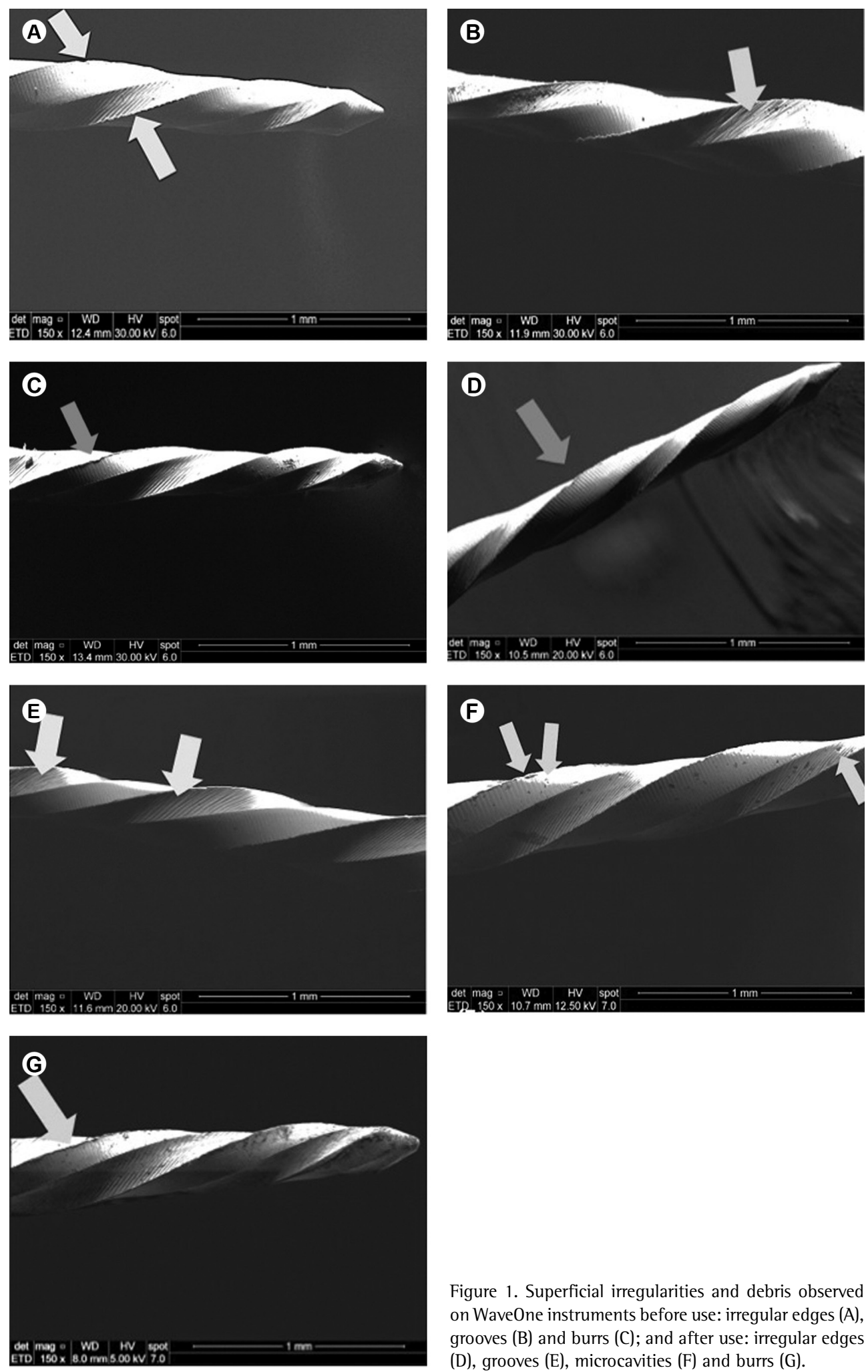

Figure 1. Superficial irregularities and debris observed on WaveOne instruments before use: irregular edges (A), grooves (B) and burrs (C); and after use: irregular edges (D), grooves (E), microcavities (F) and burrs (G). 
scores of both lengths increased after the Reciproc files were used, although no statistical significance was found. As for the WaveOne files, the mean scores decreased and this may be attributed to the fact that the reciprocating systems move back and forth, increasing contact time of the instrument's cutting blades with the dentin walls, which by itself determines wear of blades $(14,23)$, thus producing possible wear of the irregular edges and burrs seen prior to use. This reinforces the manufacturer's recommendation to use each instrument in a single molar and then discard it.

None of the 26 evaluated endodontic instruments presented fracture, different from observed by Kim et al. (8). Caballero et al. (18) observed fractures in Reciproc R25 files soon after the 12th use. Probably fracture did not occur in the present study because the instruments were used only once, as recommended by the manufacturers, and because preparation was performed by a single operator, a specialist in endodontics with experience in reciprocating systems.

The operator's experience seems to influence the fracture resistance of the instrument, although a recent study showed that the level of experience of the operator seems to have no effect on the life of the Primary WaveOne file during preparation of curved root canals (24).

Based on these findings, it may be concluded that all researched reciprocating files showed debris before and after instrumentation of the root canal system, and that WaveOne files showed more defects and deformations than the Reciproc files before and after use in the two investigated lengths.
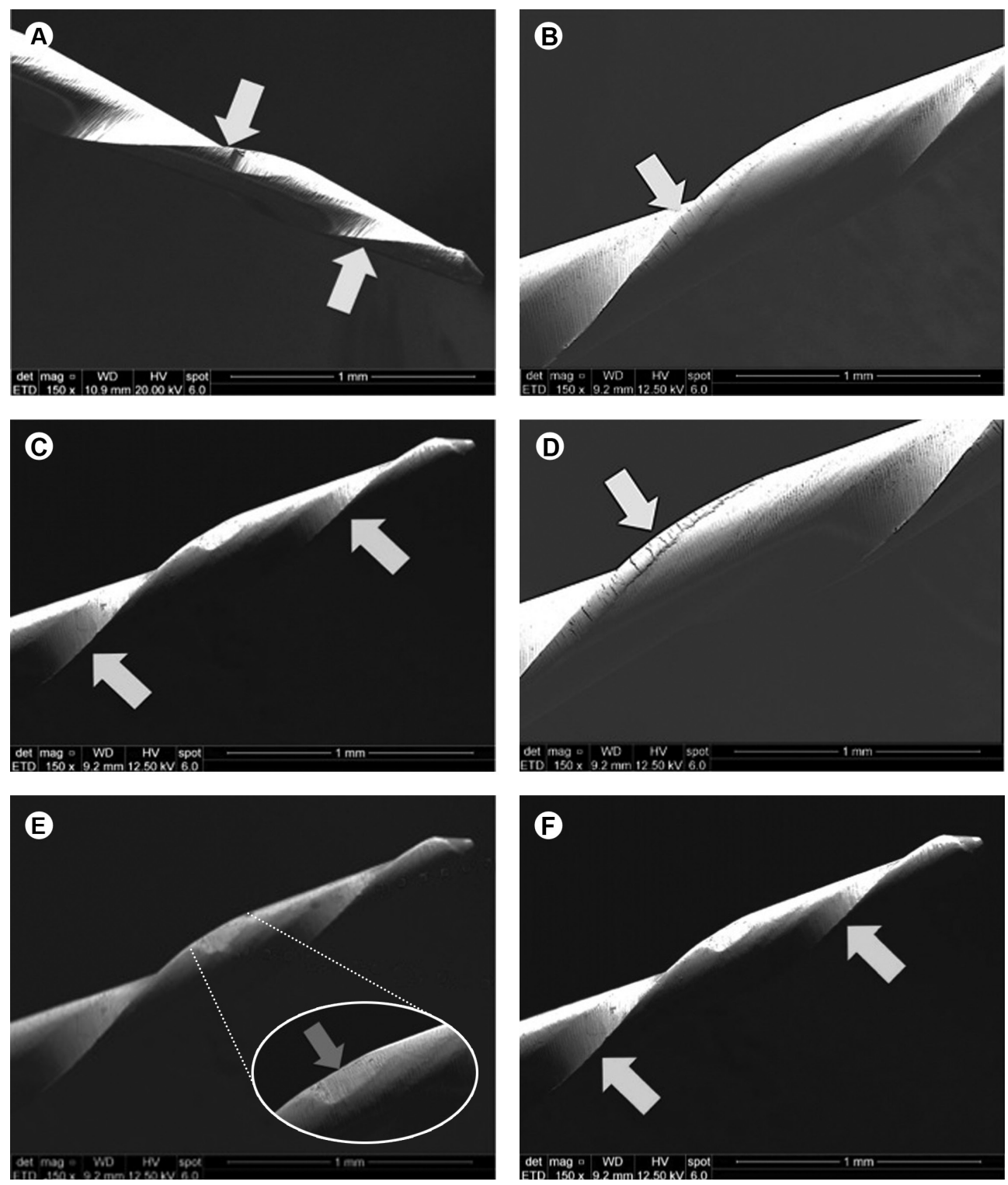

Figure 2. Superficial irregularities and debris observed on Reciproc instruments before use: irregular edges (A) and grooves (B); and after use: irregular edges (C), grooves (D), microcavities (E) and burrs (F). 


\section{Resumo}

Analisou-se por meio de microscopia eletrônica de varredura) MEV, a presença de debris, defeitos e deformações dos instrumentos endodônticos reciprocantes antes e após o preparo químico-mecânico (POM). Vinte e seis instrumentos foram divididos em 2 grupos: WaveOne $(n=13)$ e Reciproc $(n=13)$, eletromicrografados previamente ao PQM com aumento de $150 \times$, a 2 e $4 \mathrm{~mm}$ da ponta. 0 s instrumentos foram utilizados no preparo de canais radiculares mesiais de 26 molares permanentes inferiores humanos extraídos. Após, foram lavados em cuba ultrassônica e submetidos a nova análise microscópica para visualizar detritos e deformações tendo como critérios um escore que avaliou a presença ou não de borda irregular, ranhura, microcavidade e rebarba. Após análise em MEV e de posse dos escores dos avaliadores, os dados coletados foram submetidos à analise estatística descritiva pelos testes de Kruskall-Walis e Mann Whitney, ao nivel de significância de 5\%. Todos os instrumentos analisados apresentaram detritos antes e após o uso. Houve diferença estatisticamente significante quanto a defeitos e deformações entre os grupos $(p<0,05)$. A presença de defeitos e deformações foi maior nos instrumentos WaveOne, enquanto que para os instrumentos Reciproc tal indice foi menor.

\section{References}

1. Gambarini G, Gergi R, Naaman A, Osta N, Al Sudani D. Cyclic fatigue analysis of twisted file rotary $\mathrm{NiTi}$ instruments used in reciprocating motion. Int Endod J 2012;45:802-806.

2. Meireles DA, Bastos MM, Marques AA, Garcia LD, Sponchiado Júnior EC. Endodontic treatment of mandibular molar with root dilaceration using Reciproc single-file system. Restor Dent Endod 2013;38:167-171.

3. Yared GM. Canal preparation using only one Ni-Ti rotary instrument: preliminary observations. Int Endod J 2008;41:339-344.

4. Al-Hadlaq SMS, Al Jarbou FA, Al Thumairy RI. Evaluation of cyclic flexural fatigue of M-Wire nickel-titanium rotary instruments. J Endod 2010;36:305-307.

5. Johnson E, Lloyd A, Kuttler S, Namerow K. Comparison between a novel nickel-titanium alloy and 508 nitinol on the cyclic fatigue life of ProFile 25/.04 rotary instruments. J Endod 2008;34:1406-1409.

6. Gutmann JL, Gao Y, Wilkinson $\mathrm{K}$, Maxwell R, Ammon D. Evaluation of the impact of raw materials on the fatigue and mechanical properties of ProFile Vortex rotary instruments. J Endod 2012;38:398-401.

7. Lopes HP, Vieira MVB, Elias CN, Siqueira Jr JF, Mangelli M, Lopes WSP, et al.. Fatigue life of WaveOne and ProTaper instruments operated in reciprocating or continuous rotation movements and subjected to dynamic and static tests. J Endod 2013;39:693-696.

8. Kim HC, Kwak SW, Cheung GS, Ko DH, Chung SM, Lee W. Cyclic fatigue and torsional resistance of two new nickel-titanium instruments used in reciprocation motion: Reciproc versus WaveOne. J Endod 2012;38:541-544.

9. Alapati SB, Brantley WA, lijima M, Clark WA, Kovarik L, Buie C, et al.. Metallurgical characterization of a new nickel-titanium wire for rotary endodontic instruments. J Endod 2009;35:1589-1593.

10. Chianello G, Specian VL, Hardt LC, Raldi DP, Lage-Marques JL, Habitante
SM. Surface finishing of unused rotary endodontic instruments: a SEM study. Braz Dent J 2008;19:109-113.

11. Schneider SW. A comparison of canal preparations in straight and curved root canals. Oral Surg Oral Med Oral Pathol 1971;32:271-275.

12. Pruett JP, Clement DJ, Carnes DL. Cyclic fatigue testing of nickeltitanium endodontic instruments. J Endod 1997;23:77-85.

13. Troian $\mathrm{CH}$, Só MVR, Figueiredo JAP, Oliveira EPM. Deformation and fracture of RaCe and $\mathrm{K} 3$ endodontic instruments according to the number of uses. Int Endod J 2006;39:616-625.

14. Arias A, Perez-Higueras JJ, De la Macorra JC. Differences in cyclic fatigue resistance at apical and coronal levels of Reciproc and WaveOne new files. J Endod 2012;38:1244-1248.

15. Gavini G, Caldeira CL, Akisue E, Candeiro GTM, Kawakami DAS. Resistance to flexural fatigue of Reciproc R25 files under continuous rotation and reciprocating movement. J Endod 2012;38:684-687.

16. Burklein S, Hinschitza K, Dammaschke T, Schäfer E. Shaping ability and cleaning effectiveness of two single-file systems in severely curved root canals of extracted teeth: Reciproc and WaveOne versus Mtwo and Protaper. Int Endod J 2012;45:449-461.

17. Park SK, Kim YJ, Shon WJ, You SY, Moon YM, Kim HC, et al.. Clinical efficiency and reusability of the reciprocating nickel-titanium instruments according to the root canal anatomy. Scanning 2014;36:246-251.

18. Caballero $H$, Rivera $F$, Salas $H$. Scanning electron microscopy of superficial defects in twisted files and Reciproc nickel-titanium files after use in extracted molars. Int Endod J 2014; Epub ahead of print.

19. Kim HC, Kim HJ, Lee CJ, Kim BM, Park JK, Versluis A. Mechanical response of nickel titanium instruments with different cross-sectional designs during shaping of simulated curved canals. Int Endod J 2009;42:593-602.

20. Fatma Y, Ozgur U. Evaluation of surface topography changes in three NiTi file systems using rotary and reciprocal motion: An atomic force microscopy study. Microsc Res Tech 2014;77:177-182.

21. Pedullà E, Grande NM, Plotino G, Gambarini G, Rapisarda E. Influence of continuous or reciprocating motion on cyclic fatigue resistance of 4 different nickel-titanium rotary instruments. J Endod 2013;39:258261.

22. Plotino G, Grande NM, Porciani PF. Deformation and fracture incidence of Reciproc instruments: a clinical evaluation. Int Endod J 2014; Apr 22, Epub ahead of print.

23. Castelló-Escrivá R, Alegre-Domingo $T$, Faus-Matoses $V$, RománRichon S, Vicente J. Faus-Llácer VJ. In vitro comparison of cyclic fatigue resistance of ProTaper, WaveOne and twisted files. J Endod 2012;38:1521-1524.

24. Generali L, Righi E, Todesca MV, Consolo U. Canal shaping with WaveOne reciprocating files: Odontology influence of operator experience on instrument breakage and canal preparation time. 2014;102:217-222. 